\title{
El hombre galerista. ¿Podemos hablar de un arte asexuado, de forma neutra y con independencia del sexo? DEPINTRIX, DEI AUTRIX
}

\section{Juan Carlos Rubio Aragón}

Arbor CLXVIII, 663 (Marzo 2001), 355-364 pp.

Cuando comencé mi andadura como galerista hace ya trece años, la idea de presentar al público, mes tras mes, nuevas propuestas artísticas fue siempre, al igual que en la actualidad, principal causa de renovación, estímulo y alivio personal. $\mathrm{Al}$ apostar desde aquellos tiempos por el descubrimiento de nuevos artistas de mérito comprometidos con el arte de su tiempo, los dossieres y los contactos comenzaron a apilarse en nuestras estanterías con el único propósito de seguir de la mejor forma posible todos los acontecimientos que nos concernían.

En la selección de los artistas de la galería he huido de la ambigüedad muy conscientemente y he preferido siempre discursos rotundos que exponer y hacer míos a partir de su muestra, en el convencimiento de que la perseverancia en el buen trabajo rinde siempre buenos resultados a largo plazo, incluso en un pais tan mezquino como el nuestro que solo cuida a sus creadores por viejos o por muertos.

Desde el observatorio de Arteara en el Paseo del Pintor Rosales, hemos asistido al desarrollo de la profesionalización de la actividad del galerismo español y a la evolución de las actividades culturales del Estado y de sus instituciones en manera tan novedosa como desconocida en los tiempos anteriores a la transición democrática. Esta corta tradición ha afectado a todas las esferas que componen el universo cultural español, desde la crítica y el periodismo hasta las facultades de Bellas Artes, los museos y las galerías, provocando no pocas contradicciones, tensiones y hasta un modo distintivo español de acercarse al fenómeno de la cultura 
moderna. Naturalmente, ha afectado también a la misma creación que ha tenido que ponerse al día apresuradamente, en sus discursos, para globalizar, podríamos decir, sus actitudes.

Cuando en la elaboración de este texto repaso el elenco de artistas que han trabajado con la galería desde sus inicios en 1987 descubro que la proporción de mujeres es no sólo elevada sino mayoritaria. Desde este momento ya me es fácil apuntar que el dato sólo me interesa desde el punto de vista estadístico, que es como decir que el dato no me interesa. Se me ocurre que tampoco tengo clasificados a los artistas por provincias o países de origen, edad, estatura, aficiones, dominio de idiomas o preferencias sexuales.

En la misma forma en que la galería ha huido del sistema de adquisiciones por concurso al que las instituciones de nuestro país son tan proclives, prefiriendo trabajar en el fomento del coleccionismo más reposado alejado de los vaivenes del espectáculo de lo público, me digo, creo haber desconfiado siempre de actitudes radicales en lo que concierne a las militancias reivindicativas de escaso contenido artístico. Este hecho nos ha alejado de la participación en exposiciones que nos han propuesto en relación con causas más o menos nobles, en la desconfianza de sus verdaderos parámetros. En esto, hemos preferido la neutralidad a riesgo de pecar de insolidarios. Afortunadamente, el devenir de la mayoría de las mencionadas causas nos ha dado la razón y, una vez más, el alivio.

No quiero restar méritos a la contribución del arte feminista, que hoy parece moverse en clave desdibujada de postfeminismo sobre el que los distintos teóricos pueden seguir debatiendo, sino establecer diferencias entre arte feminista y arte hecho por mujeres. Es posible que cuando cada individuo disfrute de la igualdad total en todos y cada uno de los aspectos de su existencia, tanto pública como privada, se reconocerá sin duda alguna, el alcance de la importancia del feminismo, que deberá ser contemplado no tanto como una forma de corregir los errores del pasado, o de hacer permeables campos de actividad sometidos con anterioridad al total dominio del hombre, sino de garantizar la supervivencia a largo plazo de la especie.

Más allá de un escepticismo con el que confrontar la validez de las actitudes creativas basadas en posicionamientos de clase, grupo o sexo, tiene para nosotros mayor interés subrayar la aportación que realizan los distintos artistas-mujeres al contenido genérico o cuerpo cultural que la galería distribuye mes tras mes entre sus seguidores y público en general. Si por principio hemos renunciado a las reivindicaciones de naturaleza feminista o, por qué no, masculina en su contrario, ¿podemos hablar 
de un arte asexuado, producido por artistas, de forma neutra y con independencia de su sexo? Muy probablemente no: es más, resultará no sólo imposible sino de todo punto indeseable exigirle a una artista la producción de una obra tan alejada e independiente de sí misma como aquella que hiciese de su sexo un sayo.

Es absurdo insistir en que, en la selección de artistas, no hemos tenido en cuenta su sexo. Se les elige, pues, por cuanto aquí consideramos que la obra cumple los parámetros de calidad y compromiso con la investigación que nos hemos fijado. Todo ello ha podido conformar con el tiempo un estilo particular, un cuerpo de artistas al que le damos nuestro sentido común. Si nos interesa ofrecer propuestas muy diferentes, he podido comprobar que, mientras algunos artistas-hombres de la galería abordan temas propios del feminismo, otras pintoras no eluden un tratamiento de los valores de atribución masculina como pudiesen ser el gesto, la escala, el temperamento. Sería el caso de las primeras exposiciones de Consuelo Chacón.

Recuerdo aquí el debate americano en torno a las características eminentemente masculinas, por no decir machistas, del período histórico epigrafiado como expresionismo abstracto: la grandeza de los cuadros de Pollock reducidos a la consideración extrema de un arte hecho por hombres ceñidos a los estereotipos de lo masculino, incluso de lo fálico: el gesto, la grandilocuente presencia del formato, de la escala, del poder, del tamaño, de lo bestial o monumental. En ese debate importado, el informalismo español pecaría de los mismos arrastres, un arte del gesto dominado por circunloquios ajenos a lo femenino, rabiosamente masculino.

Para poner orden en nuestro discurso evocaremos ahora a la pintora española Ende, una de las primeras artistas de las que existe constancia documental y de cuyo auténtico papel en la sociedad de su tiempo no podremos saber ya mucho, desafortunadamente, que trabajó en las iluminaciones de los manuscritos del llamado Beato del Apocalipsis de Gerona, a finales del siglo VIII, firmándose Depintrix (pintora) y Dei Autrix (ayudante de Dios), siguiendo la costumbre de las mujeres nobles de su tiempo. Habrá que considerar su firma, Pintora, como una verdadera declaración de principios, que siempre quiso apostillar con la ironía implícita en la naturaleza de su labor como ayudante de monjes. Hay que decir, sin embargo, que existe cierta unanimidad entre los historiadores en el sentido de considerar el periodo feudal como de mayor relevancia para el expediente de la mujer que el posterior Renacimiento, inclinado éste muy desconsideradamente, en modos y prácticas, hacia una grandeza eminentemente masculina de la que parece haber sa- 
lido el reparto de papeles secundarios otorgados a la mujer por la historia del arte.

Mucho ha cambiado el mundo desde entonces como para obviar que la universalidad del movimiento de las mujeres ha hecho pedazos todas las expectativas de sus campeonas históricas Resulta cada día más difícil imaginar el mundo anterior a la aparición de las pioneras del feminismo en todos los ámbitos, de la religión o la educación a la salud, de la política a la ecología o lo militar. Podremos decir sin exagerar que la transmisión de estos principios a las siguientes generaciones permite vislumbrar un tiempo en el que se acepte, en forma prácticamente universal, que la democracia no estará totalmente desarrollada hasta que cada individuo disfrute de la igualdad total en todos y cada uno de los aspectos de su existencia.

En mi experiencia como galerista he dejado hacer a los artistas libremente: justo equilibrio cuando uno los escoge con la misma libertad. De ésta y no de otra relación nos hemos podido beneficiar todos/todas, en terminología de la estereotipada corrección política. Muchas de las artistas de la galería están casadas con artistas y a ellas habrá que preguntarles si existen dificultades o ventajas en esa relación, que ése es otro texto, pues hay también matrimonios de abogados, ingenieros, empresarios o deportistas. Los celos profesionales, la lucha de los lenguajes, podrán existir en el contexto de la pareja de artistas, allá donde tal vez pueda reproducirse a escala reducida lo que quede del histórico conflicto universal de los sexos, la lucha de las jerarquías o de las actitudes con respecto al lenguaje artístico, pero estas dificultades o ventajas, en su caso, afectan al discurrir de las artes lo mismo que las consecuencias de un ciclón caribeño.

Hay que insistir entonces en la separación del feminismo del arte realizado por mujeres, y concluir que el papel de la mujer, si es que como colectivo genérico ha existido en la praxis de esta galería, ha sido tan enriquecedor como el de los hombres, quienes muy probablemente tampoco han reparado en la realización de un arte marcadamente masculino. Los contenidos, como venimos diciendo y su tratamiento son lo verdaderamente importante. Por poner ejemplos, la erótica sutileza contenida en las obras realizadas con materiales de la lencería por Antonia Valero tiende a desmitificar sus propios contenidos culturales, el fetiche sobreentendido en la jerarquía masculina de valores, produciendo una muy perversa contradicción que quiere quitarle peso a lo pesado, ligereza a lo ligero, y éste es, entonces, un discurso inteligente que pretende nuevas relaciones con el espectador, en igualdad, con independencia de su sexo. 
El hombre galerista. ¿Podemos hablar de un arte asexuado,...

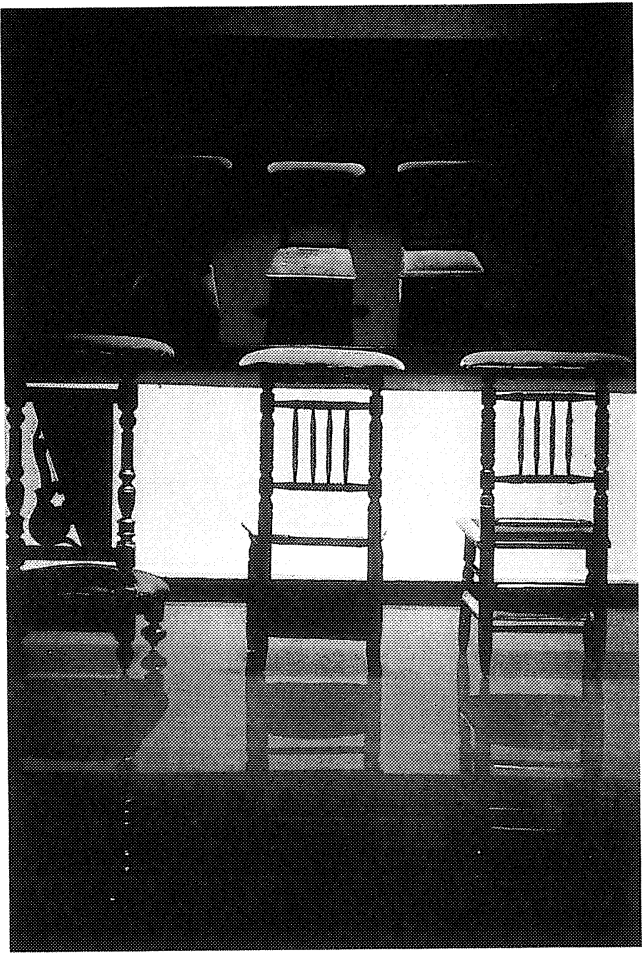

NATIVIDAD NAVALÓN.

«Lugares de ausencia». 1993.

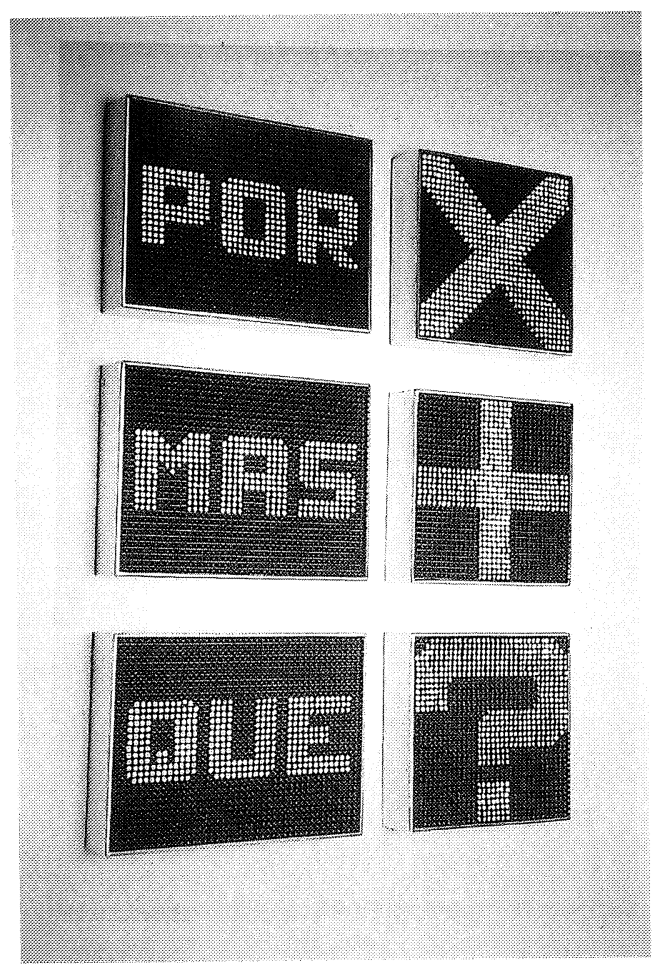

YOLANDA HERRANZ.

«Por (x) Más (+) Qué (?)». 1998.

La escultora valenciana Natividad Navalón escenografía paisajes religiosos de soledad y escudriña los mitos psicológicos de la tragedia humana, el Sida, los desterrados, la insolidaridad, la conciencia, la experiencia humana. Una reivindicación de mujer más explícita es la que realiza la artista argentina afincada en Madrid Elizabeth Aro, cuyas series de bordados antiguos sobre planos de arquitectos ilustres del siglo XX, todos ellos hombres, buscan tanto el lugar honorífico para el callado papel de la mujer-compañera como señalan los efectos de la masculinización de profesiones de singular trascendencia en la evolución de la sociedad. Los juegos semánticos de la escultora y catedrática Yolanda Herranz diseccionan los sobreentendidos del lenguaje y su relación con patrones de poder y pautas sexuales, pero su inquietante frialdad no tiene nada en común con la obra de María Cano, que prácticamente abandonó el pincel por la tijera o la máquina de fotos para cultivar una ironía autobiográfica que relaciona las obsesiones y los secretos de su proceso artístico con los artificios de la vida cotidiana. 
Nunca he preguntado a estas mujeres si se sentían pertenecientes a un supuesto colectivo de mujeres artistas, que trabajase con postulados distintos a los de los hombres artistas. Al contrario, he notado como se han podido sentir tan incómodas como escépticas ante algunas exposiciones colectivas de mujeres

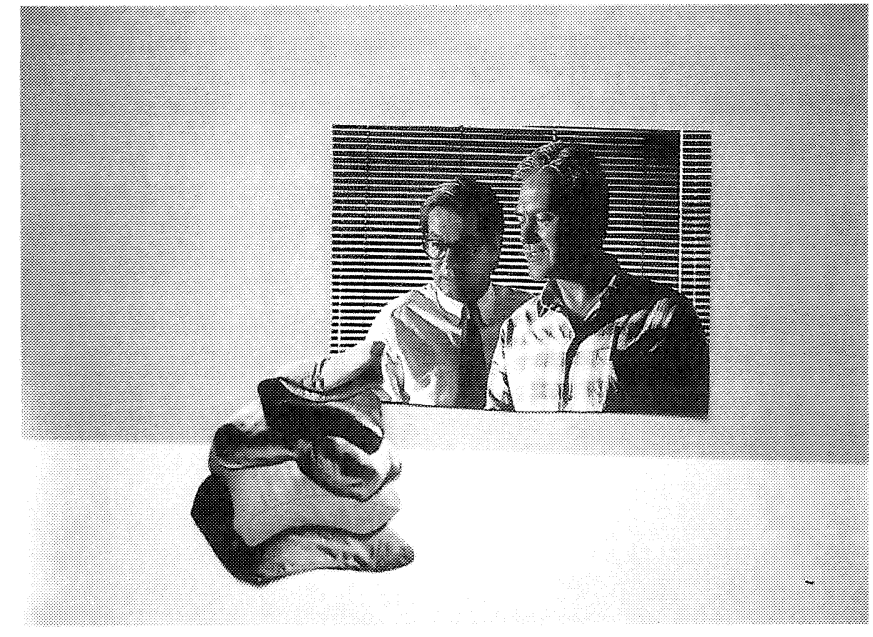

MARÍA CANO. «Raya, numera y almacena». organizadas por terceros. No quiero pensar qué hubiera pasado si se me hubiese ocurrido una exposición colectiva realizada sólo por hombres, enunciándola de esa forma. O por gays o lesbianas, ya que he de suponer que también contamos con artistas de estas tendencias sexuales, permítaseme. Muy probablemente reciba dentro de poco una propuesta afirmativa que reniegue definitivamente del sexo y habrá que atenderla.

$\mathrm{Y}$ es que, conscientes de la peligrosidad de planteamientos reduccionistas, las artistas mujeres de la galería aspiran más a trabajar en el mundo que en un mundo de hombres o de mujeres, al menos así lo creo. Cuando la pintora Eva Davidova plantea en sus obras asuntos relacionados con la conectividad, enuncia problemas vitales que implican las diferencias entre los sexos, pero sus soledades, sus enigmas, sus conflictos psicológicos son personajes autónomos construidos por la raza humana. La pu-

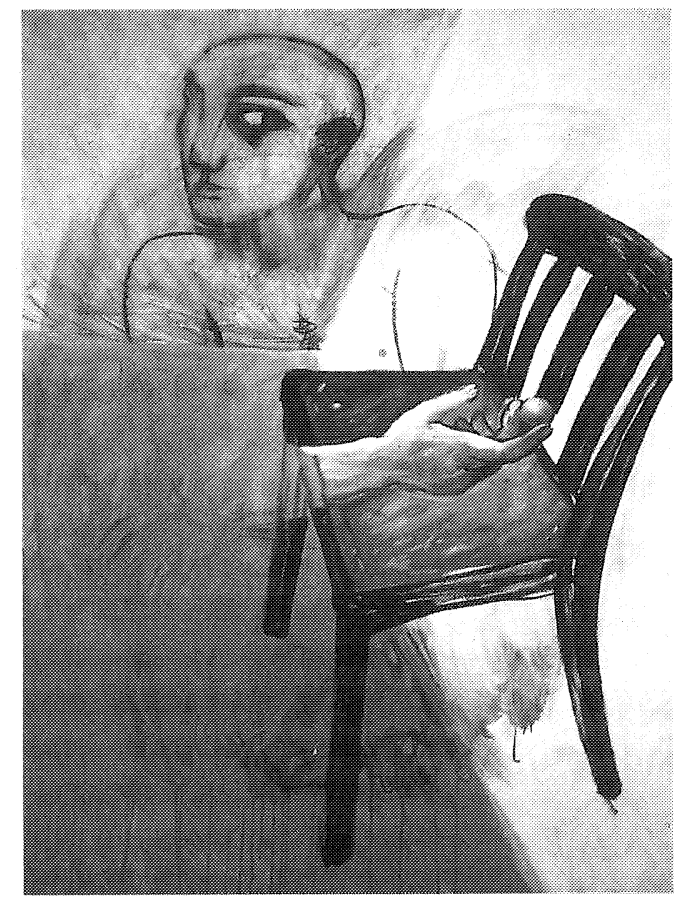

EVA DAVIDOVA. «Silla azul». 
El hombre galerista. ¿Podemos hablar de un arte asexuado,...

reza de formas y color de la obra de Rosa Rubio tiene mucho de la serenidad de una Agnes Martín, la lección del minimal, pero se entronca con la lírica de los encantamientos infantiles de Hernández-Pijoan.

Como galerista heterosexual, tampoco me he sentido incómodo ante la aparente mayoría de galeristas mujeres o galeristas homosexuales en el mundo del arte español, si es que a alguien le ha interesado esta estadística. Es muy posible que las vivencias de cada persona orienten sus decisiones y sus comportamientos. Este aspecto se lo podremos dejar a un sociólogo. Creo que de alguna forma, la situación está bastante equilibrada en la cultura española, donde llevamos años con primeras autoridades que son mujeres, homosexuales encerrados en el armario, o personas de la tercera edad que nos aportan su dilatada experiencia, y nadie parece inquietarse más allá de las dotes personales de estos cargos o de sus resultados prácticos. Se dirá que la democracia ha traído la corrección política y que la Constitución vela por nosotros, pero tal vez seamos demasiado ambiciosos si queremos que el ARTE, con mayúsculas, resuelva todos los problemas de la sociedad en que vivimos, mucho menos el problema de la relación y equilibrio entre las distintas preferencias sexuales de sus miembros y los conflictos personales. El arte que hacen los artistas de hoy, plural, es el reflejo de la sociedad de su tiempo, universal.

Cuestión muy distinta es aquello que algunos quieren llamar machismo estructural o, en su caso, modelo masculino para el arte feminista o el realizado por mujeres. Ahí está el mundo de la publicidad, nutrido todavía de los más deleznables estereotipos sexuales para reforzar las ventas de los productos más insospechados. Al igual que se discute académicamente sobre la historia o las historias de España, todavía no hemos visto un debate nacional sobre el papel de la mujer en la historia del arte español, la luz de cuyos maestros ha ensombrecido siempre el conocimiento de las «maestras», una noción que ya de por sí se habría de entender con la adjetivación adicional del arte hecho por mujeres. La palabra «maestro» evoca autoridad, poder, respeto; mientras que la noción de «maestra» implica de inmediato a la mujer, es decir el sexo. De la misma forma que, cuando se cita a un artista-hombre conocido suele bastar el apellido, Picasso o Tapies, por poner ejemplos para nombrar a una mujer de fama se utilizan nombre y apellido, Frida Kahlo o Cristina Iglesias. En este esquema, la condición moderna de la mujer artista consistiría en ejercer su arte en contradicción con su propio sexo, adaptándose a una identidad contradictoria.

Una de las escasas muestras que he organizado con la exclusiva participación de mujeres fue la exposición «Apariencias» en diciembre de 
1996. Allí participaron las artistas María Cano, Eva Davidova, Yolanda Herranz y Natividad Navalón, a quienes por adelantado y separadamente les propuse reflexionar sobre el concepto amplio de la verosimilitud, la apariencia externa de las cosas o de las situaciones, también el engaño, la aproximación el acto de aparentar, la artimaña o la misma imposibilidad del ser o del objeto absoluto. En ello estaba implícito la imposibilidad del ser completo y el juego de roles entre los sexos.

Si el resultado colectivo de la muestra fue muy interesante, no se apartó en sus individualidades del trabajo que cada artista venía realizando. Así una de las grandes conclusiones de la exposición fue que precisamente nuestra contemplación de la obra de arte termina por ser el resultado de las convenciones individuales que definen nuestro concepto de belleza. Dicho de otra forma, la dicotomía arte hecho por mujeres o arte hecho por hombres, pierde todo su sentido antagónico y se materializa con toda propiedad en la aportación individual de cada artista, cuya dotación genética resulta también moldeable por el mundo exterior, sus convenciones, su aproximación a lo absoluto, su belleza particular. Y de ahí

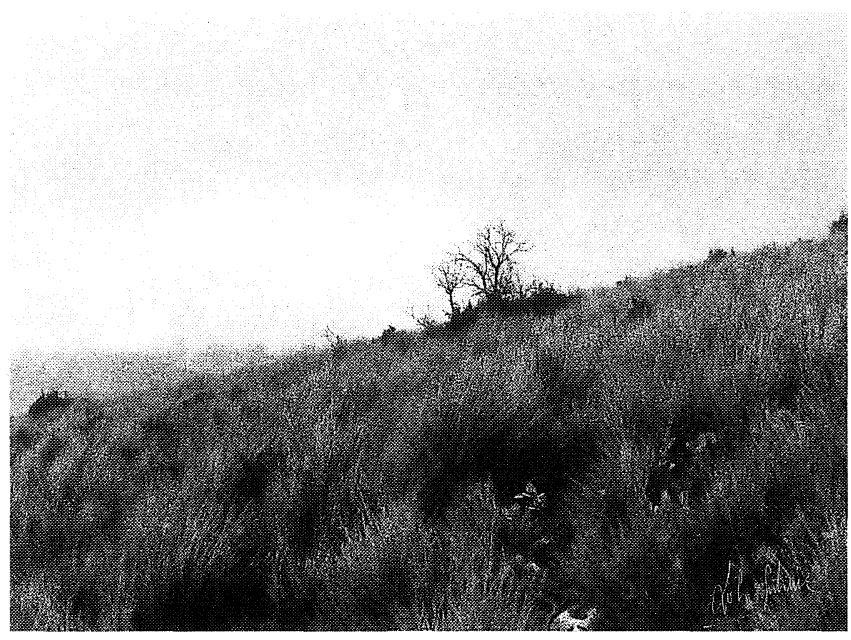

LOLA GUTIÉRREZ. «Sierra de Grajalema II». emana su interés. Por eso una fotógrafa tan pura como la gaditana Lola Gutíerrez destaca en el marasmo conceptual del que se nutren muchas instantáneas contemporáneas.

Semejante conclusión nos tranquilizó realmente, pues nos sacaba de la trampa feminista de la igualdad o de la diferencia absoluta. Si las mujeres artistas no están hoy día en permanente lucha contra la discriminación, el feminismo contemporáneo no existe. Y si las artistas de hoy no muestran interés en reparar las injusticias de la historia del Arte con el trabajo de sus antecesoras, ¿es que estamos ante una ausencia de contenidos artísticos?, ¿será que las mujeres de hoy ya disfrutan en igualdad de las conquistas y de los fracasos de la burguesía liberal dominante? 
El hombre galerista. ¿Podemos hablar de un arte asexuado,...

Los problemas del arte emergente están implícitos en su propia semántica: una ideologización del arte como inversión de valores sobreentendidos, y su opuesto, el paternalismo estructural que condena a la emergencia permanente, entre becas y concursos, como género amateur de lo intelectual, al arte producido fuera de los confines político-económicos del sistema o de las modas. A esto se añade un total desinterés por parte de las autoridades públicas en la sociedad civil, en su mal gusto, ya puestos, en el miedo a dejar que la sociedad real, aquella que define su gusto, pueda consumir lo que le viene en gana, sin necesidad de pasar por otros filtros que los de su propia existencia.

Hablar de lucha de sexos en este contexto, de reivindicaciones de los sexos en cuestiones del arte español, es un eufemismo. En un país en el que si uno es artista, y de Zamora, tiene garantizada una exposición, en Zamora, resulta peligroso colectivizar el esfuerzo bajo lemas de baja intensidad: el sexo, la religión, la denominación de origen. ¿Qué hacer con una mujer, se dirá, si además de ser artista, es extranjera? El verdadero papel del arte en la sociedad civil no debe quedar relegado a la función ornamental de la política y a los complejos de un Estado que se siente moderno pero que tiene serias dificultades para encontrar las claves de la verdadera funcionalidad de la democracia. ¿Por qué tienen tantos reparos los partidos políticos para articular definitivamente una ley que regule la participación de la iniciativa privada en actividades de carácter cultural? ¿Es que las únicas fórmulas para acercarse al fenómeno de la mujer en su amplio sentido consisten en el establecimiento de un porcentaje obligatorio de participación o en la subvención directa?

La antena de esta galería estará siempre pendiente de todos los contenidos artísticos que reflejen un compromiso con el momento que vivimos. Qué duda cabe que la gran aportación de la mujer al terreno del arte consistiría siempre en la invención de formas nuevas, no solamente plásticas, discursivas. A tràvés de su sentido, de su experiencia, encontraremos a la artista, la escritora y la observadora; también a la coleccionista, que ensambla su compromiso en una actividad de desciframiento, resultado de un esfuerzo, de una visión particular.

Si los artistas de mi galería tienen sexo, lo doy por sobreentendido; el sexo-placer nos encanta, y también resultará normal que un artista aborde cuestiones ligadas a los campos de la insatisfacción o de lo negativo. Esta no quiere ser una galería de «arte emergente», nos gusta más el arte contemporáneo, pero vendemos ilusiones caras a bajo precio. Si por naturaleza, tenemos la propensión a infravalorar nuestro trabajo y sufrimos las modas y la necesidad de convertirnos en empresas del marketing o de la comunicación, no queremos renunciar a reflexionar sobre cual- 
quier asunto. Si el universo artístico español opta por un curso suicida, o lo que es lo mismo, por el respeto a una jerarquía del pensamiento dominante a la cual someternos irremisiblemente, marginarse de la corriente central para rellenar las páginas de una fábula nebulosa y onanista es sólo una reacción más. No hay que perder la esperanza y reconducir las tentaciones escapistas en pro de una afirmación personal. Esperar a que pase la tormenta. Mejor que artistas sexuados de nuestro tiempo, es preferible ser andróginos de la idea. 